\title{
Causal and Contrastive Discourse Markers in Novice Academic Writing
}

\begin{abstract}
Causal and contrastive relations between adjacent or more distant segments of discourse play an important role in expressing coherence relations (Taboada 2006) in academic discourse including discourse written by university students of English. By overtly signalling how the writer intends the discourse segment that follows to relate to the previous segment(s), discourse markers (DMs), in particular those expressing causal and contrastive relations, contribute to cohesion and enhance the establishment and maintenance of coherence in academic written discourse ${ }^{1}$.

While analysing a corpus of Master's theses written by non-native novice writers the author attempts to find out which DMs Czech students of English use when expressing causal and contrastive relations, whether they are able to use selected DMs correctly and, in addition, whether there are any differences in the preferences of students that accord with the fields of study - linguistics, literature and culture, and methodology - in which the Master's theses are written.
\end{abstract}

\section{Key words}

Academic discourse; novice academic writing; coherence relations; causal relations; contrastive relations; discourse markers; Master's theses

\section{Creating coherence in academic written discourse}

Written discourse used in academic settings can be viewed as a purposeful interaction between writers and readers, the visible evidence of which is a text, which exists only as part of an interaction between an author/writer and a reader (Hoey 2001: 11, 187). Thus, for example, an academic textbook can be understood as the visible evidence of an interaction between an academic and his/her readers, 
in which the academic attempts to give his/her students a coherent overview of a given academic discipline. Unlike in spoken discourse, in which the entire situational context plays a crucial role in the ongoing process of 'negotiation' of meaning between all discourse participants (Povolná 2007, 2009), in written discourse, "there is no reciprocal management of the discourse" (Seidlhofer and Widdowson 1999: 209), the context is 'split' (Fowler 1986: 87), i.e. the time in which the text is decoded by the reader(s) is not simultaneous with the time in which the text is encoded by the writer, and, moreover, the situational context need not be the same. Since the written text is "only a partial record of the discourse" (Fowler 1986: 87), the writer of a research article or thesis, for example, has "to anticipate the ideas, values and expectations of the reader and to use explicit signals" (Dontcheva-Navratilova 2007: 128) such as the discourse markers under investigation in order to help the reader(s) arrive at a coherent interpretation, which, under ideal circumstances, should be as close as possible to the interpretation intended by the writer. The writer, aware of his prospective reader(s), can use some conventional signals and discourse strategies to make his/her communicative intentions clear to the reader(s). In the process of encoding as well as decoding both the writer and the reader(s) rely on the entire situational context, which also includes the background knowledge shared by the members of a particular discourse community and their prior experience of discourse processing.

"The process of creating coherent texts involves an indication of relationships between the things one is 'on about'" (Halliday and Hasan 1989: 94) because an appropriate use of signals indicating relationships between discourse segments by the writer can foster a deductive process of interpretation and understanding on the side of the reader(s). The recognition of coherence relations, i.e. "relations that hold together different parts of the discourse" (Taboada 2006: 567) by the reader enables $\mathrm{him} /$ her to perceive coherence of a text, in other words, to "assign coherence to a text" (ibid.). Coherence is understood here in harmony with Bublitz (1999: 2) as a dynamic, interpretative notion dependent on participants' comprehension and above all the entire situational context. Cohesive means, including the causal and contrastive DMs under investigation, clearly contribute to the perception of a text as coherent on condition they are used appropriately by the writer and interpreted correspondingly by the reader(s), i.e. in agreement with the writer's communicative intentions. However, it must be stressed that "cohesion is neither a necessary, nor a sufficient condition for coherence" (Bublitz 1988: 32). Although coherence is based on the language means used in the text (including selected DMs), it is also dependent on additional information provided by the entire situational context, which includes, for example, the interpreter's encyclopaedic knowledge (Miššíková 2005). Because it is not texts that cohere but rather people when they interpret and understand texts, it can even be stated that for one and the same text there exist a writer's, a reader's and an analyst's coherence, which may or may not be identical (Bublitz 1999: 2). Furthermore, since each reading of a text is performed with a particular communicative intention and in a particular context, the interpretation of the same text by the same person on different occasions need not be identical 
(Povolná 2010). Thus, it can be postulated that coherence and the quality of being coherent are important in particular when expressing the semantic relations often considered most informative of all (Kortmann 1991), i.e. causal and contrastive relations, notably in novice academic writing.

\section{DMs and semantic relations important in academic written discourse}

Adjacent or more distant segments of discourse ${ }^{2}$ whose relationship is indicated by some explicit guiding signals are usually processed more easily and thus faster (Haberlandt 1982) than segments without any overt indication of the relationships intended by the writer. If the reader cannot rely on any lexical clue in his/her interpretation of the writer's communicative intentions, he/she may face problems in arriving at a coherent interpretation and adequate understanding of the text. However, the writer, who is usually aware of the reader and his/her efforts to arrive at an interpretation intended by the author, tends to use certain overt guiding signals such as selected DMs, which can contribute to better organization of the discourse and "clarify the progress of the writer's argumentation" (DontchevaNavratilova 2009: 34).

Causal and contrastive relations, which rank among the most informative and at the same time most complex semantic relations that can hold between segments of discourse (Kortmann 1991: 160-164), tend to be marked explicitly, notably in academic written discourse, whose important feature is the presenting and supporting of arguments (Biber et al. 1999: 880). However, the more specific type of cause and/or contrast/concession a given marker signals is influenced by the entire context, both linguistic and non-linguistic, since "a text is not coherent in itself but is understood as coherent in an actual context" (Bublitz 1988: 32), in which the current reader attempts to interpret the text as discourse by relating it to his/her background knowledge and previous experience of processing similar types of discourse.

Discourse markers ${ }^{3}$, namely those expressing causal and contrastive relations, are viewed here, in conformity with Fraser $(1990,1999)$, as a class of commentary pragmatic markers signalling relationships between segments of discourse, hence contributing to both cohesion and coherence. By signalling how the writer intends the current basic message that follows to relate to the previous discourse, these language means perform in particular text-organizing functions, thus being viewed primarily as cohesive means which "reflect underlying connections between propositions" (Schiffrin 1987: 61). The DMs selected for this inquiry are expected to occur frequently in the data analysed, since their frequent use in academic written discourse is regarded as a reflection of the writer's need to present and support his/her arguments to an academic audience in a straightforward and comprehensive way (for differences between academic texts written in English and Czech, see e.g. Chamonikolasová 2005), and that the frequent use of DMs reflects "the characteristic choice of this register to mark the links between ideas overtly" (Biber et al 1999: 880). 
DMs as explicit signals of "a relationship between the interpretation of the segment they introduce [or they are part of], S2, and the prior segment, S1" (Fraser 1999: 931) impose "on S2 a certain range of interpretations, given the interpretation(s) of S1 and the meaning of the DM" (Fraser 1999: 942). Owing to their crucial role in the expression of coherence relations and in the organization of the discourse, DMs can be understood as "part of the more general analysis of discourse coherence" (Schiffrin 1987: 49).

\section{Causal and contrastive discourse markers under investigation}

The analysis is concerned with causal and contrastive relations obtaining at clausal and higher levels of discourse, since it is assumed, together with Fraser (1999: 939-940), that at these levels the markers relate two separate messages, hence functioning as DMs (Example 1), while at a lower level they function as conjunctions within single messages (Example 2), thus being outside the scope of the present analysis.

(1) The spoken and written language of the Britons gradually altered its form, both structurally and lexically. As a consequence, a great amount of English word stock is of Latin and French origin. (Linguistics, Text 1)

(2) This attitude refers to Cato's forfeit of God and truth and in consequence his damnation.

(Literature and culture, Text 2)

From the morphological viewpoint, the DMs under investigation are drawn primarily from conjunctions (e.g. as, because, since, although, but, while), adverbs (e.g. therefore, thus, however, nevertheless, yet) and prepositional phrases (e.g. in contrast, on the other hand). However, they "do not play the role in a sentence that their classes would suggest, but instead, they are separate from the propositional content" (Fraser 1999: 302) and their meaning is procedural rather than conceptual. The author/writer uses DMs intentionally in order to enable his/her reader(s) to derive meaningful discourse from the text. If a marker is absent, the propositional content of the respective discourse segments remains the same, as would be the case in Example 3 without the marker in consequence; however, without any guiding signal it could be more difficult for the reader(s) to arrive at the interpretation intended by the author.

(3) Pupils at upper-primary school are considered to be basic users and their knowledge of the second language is not at high level. In consequence, feedback can be in their mother tongue.

(Methodology, Text 1) 
As far as a syntactic viewpoint is concerned, both causal and contrastive DMs can be subdivided into DMs expressing hypotactic relations and those involved in paratactic relations. The reason for this subdivision is the expected difference between the two syntactic groups in the frequency of occurrence within both causal and contrastive DMs selected for the analysis. The hypotactic relation is usually expressed overtly by certain markers, such as as, because, since, and although, while, even if (all listed by decreasing frequency within their respective semantic classes), while the paratactic relation, apart from being indicated by certain markers, such as thus, therefore, so, consequently, and but, however, on the other hand, nevertheless, yet (also listed by decreasing frequency), can often remain explicitly unexpressed; this does not mean that there cannot be certain semantic clues in the respective discourse segments, such as nouns, verbs, adjectives (e.g. contrast, contrasting), prepositional phrases (e.g. because of, on account of, in spite of, in contrast to; for the last one listed, see Example 4), or other ways of expressing cause or contrast; these possibilities, however, have remained outside the scope of the present analysis.

(4) As conversation is organised in a different way from writing, it evidently lacks clear sentence boundaries. It is related to inexplicitness in speech. There is often no need to finish a sentence thanks to shared knowledge. It means that clauses, rather than sentences, may be left unfinished in contrast to written language where sentences require finalisation and completeness. (Linguistics, Text 3)

Concerning concession it is worth stating that concession is viewed here as a special case of contrast, namely one existing between the expected/usual causal relationship and the actual situation (Dušková et al 1988, Fraser 1999). Therefore, contrastive DMs included in the analysis subsume markers expressing contrast as well as concession, since "in some cases, elements of contrast and concession are combined in uses of linking adverbials" (Biber et al 1999: 878), and it is not always possible to draw a strict borderline between these two semantic groups. Even though Biber et al (1999: 879) suggest grouping markers expressing contrast and concession according to whether their primary meaning focuses on contrast (e.g. instead, conversely, in contrast) or concession (e.g. nevertheless), with regard to the reasons stated above, such a distinction is not drawn in this study.

As regards the frequency of occurrence of DMs expressing hypotactic and paratactic relations, it must be noted that since the paper deals with academic written discourse, in which clear argumentation and support of authors' own standpoints play a crucial role, a high number of overtly expressed markers, in particular those occurring in hypotactic relations, is expected, because these are mostly marked overtly and, as stated in Taboada (2006), the semantic relations of cause and concession are "typically expressed through subordination" (2006: 576). 


\section{Material}

The investigation is based on a corpus of fifteen Master's theses written by students of English in their final year of study at the Department of English Language and Literature at the Faculty of Education, Masaryk University, Brno in the period from 2005 to 2008. Students intending to write their theses in English have to choose a topic from the areas of linguistics, literature and culture, or methodology.

The whole corpus amounts to approximately 254,000 words and can be subdivided into three subcorpora, each comprising five Master's theses representing a different area of study chosen according to students' interests and preferences. (For the total length of the texts analysed by field of study, see Tables 1 and 2 in Sections 5 and 6 below respectively.) In order to get comparable data for the analysis it has been necessary to exclude from the analysis all parts of texts which comprise tables, figures, graphs, references, sources, quotations, and, in the case of methodology theses, lesson plans prepared by students as part of their research. In addition, most of the results discussed and exemplified have been normalized for the frequency of occurrence of the selected markers per 1,000 words or given in percentages of occurrence.

Although the corpus is relatively small in size, it is considered sufficient for the present study, since, in harmony with Flowerdew (2004: 18), it is assumed that specialized corpora are more appropriate than large general corpora for an analysis of particular language phenomena such as DMs in one particular genre (For lexical bundles studied in the same corpus, see Dontcheva-Navratilova in this volume).

It remains to be noted that there are also marked differences between theses written within the same area, which supports my assumption that differences between fields of study such as linguistics and methodology are caused by particular students' knowledge of the language means under scrutiny, overt instructions provided by teachers of academic writing and field-specific guidance by thesis supervisors and resulting preferences in students' writing skills and habits.

\section{Causal DMs: Results}

Table 1 provides evidence that in novice academic writing causal relations expressed by explicit hypotactic DMs, although realized by three different markers only (as, because and since), tend to be slightly more frequent (506 occurrences; 1.99 tokens per 1,000 words) than those expressed by explicit paratactic markers (482 occurrences; 1.89 tokens per 1,000 words). This result is in agreement with my expectation that hypotactic relations are usually marked overtly in academic discourse. In contrast to the hypotactic markers, all of which are found relatively frequently in all the data (1.89-2.15), the paratactic markers are rather unevenly distributed, some of them having a frequency of occurrence of less than ten to- 
kens (0.04) in the whole corpus; owing to their rather limited use, the paratactic markers as a consequence (2 occurrences), hence (8), for (8), in consequence (3), now (2), of course (zero) and somehow (2) have been excluded from Table 1 , although they are included in the last two lines of the table. (See e.g. 2.85/2.93 in the first column, where 2.85 is the frequency of occurrence of paratactic DMs per 1,000 words listed in the table, while 2.93 equals the total frequency of occurrence of all paratactic DMs found in the linguistics subcorpus.) Of the fifteen different types of paratactic causal markers searched for during the analysis only eight (more than half) occur with noteworthy frequency, i.e. ten or more occurrences in the whole corpus; these are all listed in the following table.

Table 1. Most frequent DMs for hypotactic and paratactic causal relations in students' theses according to different fields of study

\begin{tabular}{|l|c|c|c|c|c|}
\hline No. of words in texts & $\mathbf{8 7 , 6 3 6}$ & $\mathbf{7 8 , 2 0 6}$ & $\mathbf{8 8 , 6 2 8}$ & \multicolumn{2}{|c|}{ Total: 254,470 } \\
\hline Hypotactic DMs & Linguistics & Literature & Methodology & $\begin{array}{c}\text { per 1,000 } \\
\text { words }\end{array}$ & $\begin{array}{c}\text { No. of } \\
\text { occur. }\end{array}$ \\
\hline as & 0.62 & 1.02 & 0.99 & 0.87 & 222 \\
\hline because & 0.94 & 0.86 & 0.77 & 0.85 & 217 \\
\hline since & 0.34 & 0.27 & 0.18 & 0.26 & 67 \\
\hline All hypotactic DMs & $\mathbf{1 . 8 9}$ & $\mathbf{2 . 1 5}$ & $\mathbf{1 . 9 4}$ & $\mathbf{1 . 9 9}$ & $\mathbf{5 0 6}$ \\
\hline Paratactic DMs & Linguistics & Literature & Methodology & $\begin{array}{c}\text { per 1,000 } \\
\text { words }\end{array}$ & $\begin{array}{c}\text { No. of } \\
\text { occur. }\end{array}$ \\
\hline accordingly & 0.01 & 0.04 & 0.07 & 0.04 & 10 \\
\hline as a result & 0.10 & 0.03 & 0.02 & 0.05 & 13 \\
\hline consequently & 0.19 & 0.14 & 0.17 & 0.17 & 43 \\
\hline (and) so & 0.41 & 0.06 & 0.23 & 0.24 & 61 \\
\hline so that & 0.06 & 0.03 & 0.12 & 0.07 & 18 \\
\hline therefore & 0.96 & 0.32 & 0.41 & 0.57 & 145 \\
\hline thus & 0.99 & 0.23 & 0.47 & 0.58 & 147 \\
\hline then & 0.13 & 0.04 & 0.07 & 0.08 & 20 \\
\hline All paratactic DMs & $\mathbf{2 . 8 5 / 2 . 9 3}$ & $\mathbf{0 . 8 8} / \mathbf{1 . 0 2}$ & $\mathbf{1 . 5 6 / 1 . 6 4}$ & $\mathbf{1 . 8 0 / 1 . 8 9}$ & $\mathbf{4 5 7 / 4 8 2}$ \\
\hline TOTAL DMs & $\mathbf{4 . 8 3}$ & $\mathbf{3 . 1 7}$ & $\mathbf{3 . 5 8}$ & $\mathbf{3 . 8 8}$ & $\mathbf{9 8 8}$ \\
\hline
\end{tabular}

As Table 1 indicates, some markers are very frequent, such as as (222), because (217), thus (147), and therefore (145) (listed by frequency of occurrence), or relatively frequent, i.e. more than forty occurrences in the whole corpus, such as since (67), so (61), and consequently (43). However, the most frequent hypotactic markers of all, as and because, as well as the most frequent paratactic ones, thus and therefore, represent more than three quarters of all tokens within their respective syntactic groups. Hence, it can be concluded that students prefer to use a relatively limited repertoire of the more common DMs (i.e. as, because, thus and/or therefore) than resorting to a wider choice of markers which are at their disposal, notably when expressing paratactic causal relations. Finally, it should be stressed that there are differences between the three fields of study, for example, between Master's theses written in the area of linguistics (4.83) and those concerned with 
methodology (3.58), in terms of both types and tokens of DMs students use when expressing causal relations. As already stated, these can be caused in particular by students' comprehension and individual preferences in writing habits resulting from overt field-specific instructions provided by thesis supervisors, which, for example, in the case of linguistics-oriented theses has led to the overuse of certain more frequent DMs.

\section{Contrastive DMs: Results}

My results drawn from the analysis of contrastive DMs are given in Table 2. It brings evidence that, contrary to my expectation, contrastive relations expressed by hypotactic DMs are considerably less frequent (297 cases; 1.17 tokens per 1,000 words) in the data than those expressed by paratactic DMs (1,152 cases; 4.53 tokens per 1,000 words), although hypotactic relations are usually marked overtly in discourse (see above). The most interesting and striking result in Table 2 is the uneven distribution of the contrastive markers under examination (altogether 1,449 occurrences) in terms of both types and tokens. Of the thirty-eight different types of contrastive DMs included in the analysis only fifteen occur with noteworthy frequency, i.e. having fifteen or more occurrences in the whole corpus; this only concerns six hypotactic markers out of the nine selected for the analysis, and nine paratactic DMs out of the twenty-nine searched for in the data.

As follows from Table 2, some markers are very frequent, such as but (566 cases) and however (222), or relatively frequent, i.e. having more than forty occurrences in the whole corpus, such as although (101), on the other hand (81), nevertheless (63), yet (61), and while (44) (listed by frequency of occurrence). Of these, the paratactic marker but (566) is almost as frequent as all the other paratactic markers put together (586) and almost six times more frequent than the most common hypotactic marker although (101) (for comparison, see e.g. Altenberg 1986).

Table 2. Most frequent DMs for hypotactic and paratactic contrastive relations in students' theses according to different fields of study

\begin{tabular}{|l|c|c|c|c|c|}
\hline No. of words in texts & $\mathbf{8 7 , 6 3 6}$ & $\mathbf{7 8 , 2 0 6}$ & $\mathbf{8 8 , 6 2 8}$ & \multicolumn{2}{|c|}{ Total: 254,470 } \\
\hline Hypotactic DMs & Linguistics & Literature & Methodology & per 1,000 words & No. of occur. \\
\hline although & 0.37 & 0.56 & 1.83 & 0.40 & 101 \\
\hline even if & 0.06 & 0.35 & 0.96 & 0.17 & 43 \\
\hline even though & 0.21 & 0.03 & 0.01 & 0.13 & 32 \\
\hline though & 0.24 & 0.05 & 0.11 & 0.14 & 36 \\
\hline while & 0.19 & 0.23 & 0.10 & 0.17 & 44 \\
\hline whereas & 0.21 & 0.29 & 0.06 & 0.12 & 30 \\
\hline All hypotactic DMs & $\mathbf{1 . 2 7 / 1 . 3 5}$ & $\mathbf{1 . 3 0 / 1 . 3 6}$ & $\mathbf{0 . 8 2 / 0 . 8 2}$ & $\mathbf{1 . 1 2 / 1 . 1 7}$ & $\mathbf{2 8 6 / 2 9 7}$ \\
\hline
\end{tabular}




\begin{tabular}{|l|c|c|c|c|c|}
\hline Paratactic DMs & Linguistics & Literature & Methodology & per 1,000 words & No. of occur. \\
\hline but & 2.05 & 2.86 & 1.83 & 2.22 & 566 \\
\hline however & 0.66 & 1.01 & 0.96 & 0.87 & 222 \\
\hline instead & 0.08 & 0.09 & 0.01 & 0.06 & 15 \\
\hline nevertheless & 0.39 & 0.24 & 0.11 & 0.25 & 63 \\
\hline nonetheless & 0.11 & 0.04 & 0.07 & 0.07 & 19 \\
\hline on the other hand & 0.41 & 0.29 & 0.25 & 0.32 & 81 \\
\hline still & 0.23 & 0.10 & 0.12 & 0.15 & 39 \\
\hline though & 0.18 & 0.04 & 0.02 & 0.08 & 21 \\
\hline yet & 0.64 & 0.05 & 001 & 0.24 & 61 \\
\hline All paratactic DMs & $\mathbf{4 . 7 6 / 5 . 1 3}$ & $\mathbf{4 . 7 3 / 4 . 9 1}$ & $\mathbf{3 . 3 8 / 3 . 5 9}$ & $\mathbf{4 . 2 7 / 4 . 5 3}$ & $\mathbf{1 , 0 8 7 / 1 , 1 5 2}$ \\
\hline TOTAL DMs & $\mathbf{6 . 4 8}$ & $\mathbf{6 . 2 7}$ & $\mathbf{4 . 4 1}$ & $\mathbf{5 . 6 9}$ & $\mathbf{1 , 4 4 9}$ \\
\hline
\end{tabular}

The following DMs have been excluded from Table 2, although, similarly to Table 1, they are listed in the lines which give total numbers of contrastive DMs. The exclusion concerns the hypotactic markers albeit (zero occurrence), at any rate (zero), by comparison (zero), despite the fact (that) (7), except (that) (1), in comparison (zero), in spite of the fact (that) (3), and or else (zero), and the paratactic DMs actually (4 occurrences), after all (2), all the same (2), alternatively (1), anyhow (1), anyway (5), at the same time (9), besides (2), by contrast (1), conversely (5), in any case (1), in contrast (7), in spite of that (3), notwithstanding (zero), on the other side (1), and oppositely (zero). As stated in Altenberg (1986), with markers such as albeit, notwithstanding and oppositely, zero occurrence is not at all surprising, since these markers are not likely to appear in any corpus of contemporary English.

Concerning the overall frequency of occurrence and above all the distribution of individual types of markers selected for this study, it can be postulated that, as with the choice of causal DMs, students do not frequently resort to the whole repertoire of DMs that are at their disposal; the spectrum of DMs novice writers really choose to use when expressing contrastive relations (15 types) is broader than that of causal markers (11 types); this difference can be caused by the much wider availability of contrastive markers (38 types) than causal markers (18 types) and also by students' ability to use a relatively wide repertoire of causal markers, i.e. eleven of 18 different types. (For differences between the more frequent DMs, which are explicitly listed, and the total number of DMs found in the data, see Tables 1 and 2 above.)

\section{Position of selected DMs in the sentence structure: Results and exemplifications}

Subordinate clauses introduced with a hypotactic marker can either precede or follow their superordinate clauses; in other words, clauses providing background information, which have a 'grounding' function in discourse (Altenberg 1986), 
can come either before or after clauses in which some cause or contradiction is expressed. This is illustrated by examples taken from the texts in which the DMs in question occur most frequently of all. (For causal DMs, see Examples 5 and 6, and for contrastive ones, see Examples 7 and 8; in addition, Example 7 illustrates one of the typical mistakes novice writers make, notably the use of a comma after a hypotactic marker.)

(5) As participants can feel defensive about the immediate discussion of their 'performance' in the role play, a structured de-briefing is recommended. (Methodology, Text 4)

(6) It would be very oblivious not to mention the last term concerned, that of transition, because it stands in between the theme and rheme and contributes to the development of $\mathrm{CD}$ and communication as such. (Linguistics, Text 1)

(7) Although, they try to live their lives as if nothing has happened it is a very difficult task for all of them. The whole house seems to fall asleep and all the children start to live in their own way. (Literature and culture, Text 4$)^{4}$

(8) The non-properly prepared speaker may start his turn with a filled pause while the prepared one usually uses expressions like well.

(Linguistics, Text 3)

Table 3. Position of most frequent hypotactic causal and contrastive DMs

\begin{tabular}{|l|c|c|c|c|}
\hline All theses together & \multicolumn{3}{|c|}{ Position } & \\
\hline Causal DMs & I & M & F & TOTAL \\
\hline as & 70 & 1 & 151 & 222 \\
\hline because & 7 & 0 & 210 & 217 \\
\hline since & 25 & 0 & 42 & 67 \\
\hline Total (No.) & $\mathbf{1 0 2}$ & $\mathbf{1}$ & $\mathbf{4 0 3}$ & $\mathbf{5 0 6}$ \\
\hline Total (\%) & $\mathbf{2 0 . 2}$ & $\mathbf{0 . 2}$ & $\mathbf{7 9 . 6}$ & $\mathbf{1 0 0 . 0}$ \\
\hline Contrastive DMs & $\mathbf{I}$ & $\mathbf{M}$ & $\mathbf{F}$ & TOTAL \\
\hline although & $\mathbf{7 5}$ & 2 & 24 & 101 \\
\hline even if & 26 & 1 & 16 & 43 \\
\hline even though & 20 & 1 & 11 & 32 \\
\hline though & 6 & 8 & 22 & 36 \\
\hline while & 19 & 0 & 25 & 44 \\
\hline Total (No.) & $\mathbf{1 4 6}$ & $\mathbf{1 2}$ & $\mathbf{9 8}$ & $\mathbf{2 5 6}$ \\
\hline Total (\%) & $\mathbf{5 7 . 0}$ & $\mathbf{4 . 7}$ & $\mathbf{3 8 . 3}$ & $\mathbf{1 0 0 . 0}$ \\
\hline
\end{tabular}

Overall results concerning the position of subordinate clauses introduced with a hypotactic marker expressing both causal and contrastive relations are presented in Table 3. These results testify that hypotactic causal DMs tend to occur in final 
(F) position in the sentence complex (Tárnyiková 2007: 24), i.e. when introducing a subordinate clause which follows its superordinate clause (about $80 \%$ of all hypotactic causal markers). This concerns in particular the overwhelming majority of occurrences of because (210 cases), although the initial (I) position of a subordinate clause in the sentence complex is also common (about $20 \%$ of all hypotactic causal markers, represented mostly by as in my data).

With hypotactic contrastive DMs, the situation is slightly different since there is a common preference for the initial position of a subordinate clause introduced with a hypotactic marker ( $57 \%$ of the contrastive markers included in the table). This result is in agreement with Altenberg (1986: 22), who holds the view that "although-clauses tend to be most frequent in initial position". The reason for this can be a tendency to order discourse segments in a natural way, which entails the placement of a discourse segment with known information first, as with as in Example 5 or although in Example 7 above, i.e. before new information or some new aspect within it (for the 'basic distribution of CD', see Firbas 1992). By contrast, though used as a hypotactic marker dominates in final position in the sentence complex (22 occurrences) and it is relatively frequent in medial (M) position ( 8 occurrences; see Example 11 below). It can now be stated in conformity with Altenberg (1986: 22) that although (75 cases) is selected for the 'grounding' function much more frequently than though (6 cases) in the data analysed.

(9) It is evident from the previous statement that in order to communicate both types of skill have to be employed. However, there is still another step to be taken in the long and effortful process of learning to speak a second language. (Methodology, Text 5)

(10) All the instances of $\mathrm{m} \mathrm{hm}$ in the example above merely function as continuers. They do not express any particular listener's attitude to what is said and only endorse the current speaker to continue his turn. Thus backchannels are classified as continuers.

(Linguistics, Text 3)

The above-mentioned 'natural' way of sequencing discourse segments from known to new information explains a general preference for the use of coordination rather than subordination in the material, since coordination enables the placement of background information first, i.e. in the prior discourse segment, and that of new, unexpected information in the subsequent segment which comprises a DM. (For illustration of some paratactic markers frequently used within their respective semantic classes, see Examples 9 and 10.) This tendency is clearly evidenced by my results concerning contrastive relations in particular (see Table 2 above), in which paratactic DMs (about 1,150 cases), which are always used in a subsequent discourse segment, unambiguously dominate over hypotactic markers (about 300), although hypotactic markers can also be used in the subsequent 
segment of discourse, i.e. in final position within the sentences complex. This possibility is represented by about 38 per cent of the contrastive DMs included in Table 3 and illustrated by the marker while in Example 8. With causal relations, this natural sequencing of discourse segments is more common (about $80 \%$ ).

(11) Turn-taking may present a problem for learners. The action itself, though native speakers may not even realize it, is quite complex. (Methodology, Text 5)

As already stated, the medial position of a subordinate clause introduced with a hypotactic marker is also represented in the data, most frequently by the hypotactic marker though, shown in Example 11. However, such cases represent less than 5 per cent of hypotactic contrastive DMs listed above and only a single occurrence of the causal marker as (see Table 3).

\section{Exemplification and discussion of novice writers' use of selected DMs in different fields of study}

Let me now exemplify and discuss some of the selected DMs as used by novice writers, i.e. students of English writing their Master's theses in different fields of study.

(12) The purchase of such a (often very expensive) car, although it has become nearly a necessity for some people, can be still partly considered as a matter of rather social needs. Various social groups identify themselves through shared attitudes, manners and habits of consumption. The importance of the capitalist system for a meaningful existence of advertising is mentioned also by Cook (1992: 13).

As for former socialist Czechoslovakia, it was definitely also a matter of social recognition to own a good car. However, until the Velvet revolution there was a lack of cars produced and there were perhaps even more potential consumers than products. Besides, fewer cars had been exported from abroad and thus practically no competition existed. Under such conditions hardly any expensive and imaginative advertising was needed. They were not producers who needed to try hard to sell their cars, but, on the contrary, they were customers who needed to try hard to get a car somehow. (Linguistics, Text 5)

Example 12 is a piece of text taken from the group of linguistics theses (see Table 1 and 2 above) in which students often tend to overuse markers they know and thus are mostly able to use them correctly (for similar results, see Vogel 2008, Wagner 2011). The author of the thesis in Example 12 uses a contrastive or causal DM in almost every other sentence. However, unlike some other au- 
thors included in the investigation, she is able to use quite a wide repertoire of mostly paratactic DMs; for example, in order to express contrastive relations in her thesis she uses 18 different paratactic and eight different hypotactic tokens of DMs (for illustration, see although, still, however, besides, but and on the contrary in the above example). As regards the causal markers thus (see Example 12) and therefore, my results have proved that the individual authors mostly use either thus or therefore, in accordance with their preferences; only authors who are able to use a relatively wide repertoire of causal markers apply both of the above-mentioned markers to express causal relations. It is also worth noting here that the causal markers therefore and thus, along with the contrastive however (the last two DMs illustrated in Example 12), have been found in Biber et al (1999: 885) to represent the most common markers of all in academic texts produced by native speakers of English.

(13) This example illustrates the situation when yeah in the speaker B's second turn serves as a response to the speaker A's question about pouring the tea. Another important feature should be introduced since it appears in the example above. The last turn of the transcription contains an unrecognised syllable which can be reckoned as an unknown backchannel item since thanks to its shortness it is most probable that the expression does not serve as a turn; the contention being based on the analyser's cultural knowledge.

The following example is an instance of a short response serving as a greeting, but not as a backchannel.

Here the B's last response yeah, bye is classified as a turn since it is not a supportive device which provides the current speaker the information that he is listened to and should continue in his speech.

(Linguistics, Text 3)

Example 13 is another illustration of the excessive use of the selected DMs, this time showing the hypotactic causal marker since, which the author of a linguistics thesis uses most frequently (in 29 cases) of all fifteen novice writers included in the investigation, thus being responsible for the overwhelming majority of occurrences of since, not only in the linguistics subcorpus (only 30 occurrences) but also in the corpus as a whole (67 occurrences). This finding is in accordance with my expectation that some students tend to resort to certain markers they know and thus are able to use correctly.

(14) The insufficient communicativeness before the mother's death has caused that the children are lost in the reality and do not know how to behave. On the other hand, all their arguments should be understood as an act of unity and love. The worst thing which could happen to them is their separation. Even if the reader should be disgusted he should feel sorry for the children at least a bit. The way they behave is not their fault only, it is closely connected with the whole family and their previous upbringing. They were 
taught to act together, to support and defend themselves against the others. Julie, however, as an almost-adult person, who is supposed to decide, does not want to rid of the freedom, the power she has over all her siblings and decides to bury their mother into the trunk down in the cellar. (Literature and culture, Text 4)

Example 14, which is taken from the corpus of literature and culture theses, illustrates that some non-native speakers of English tend in their novice writing to use rather a limited repertoire of the selected markers, the most frequent ones being but, however, although and on the other hand (the last one frequently used probably under the influence of the Czech phrase na druhé straně). Two of the DMs listed are included in Example 14. In fact, if the marker even if ${ }^{5}$ is added to the list, then it can be stated that the author of the thesis in the above example hardly ever uses any marker other than those mentioned, since of the 212 contrastive markers the writer uses in the whole study, 171 tokens are represented by the markers listed immediately above.

(15) Patin's song could be presented in any other southern state since it resembles one of the many plantation songs from the era of slavery. Accordingly, the topic of white versus black relations, which was described previously, is a general southern topic to discuss. The southern themes, such as black music and race relations, mingle with the themes which are typical for Louisiana - Cajuns and Creoles.

(Literature and culture, Text 3)

Although it cannot be exemplified here owing to the lack of space, it should be stated that some authors of literature and culture theses in particular tend to cumulate certain DMs at the beginning or at the end of their theses, above all when introducing and concluding their arguments, while using hardly any other markers in most of the main text, not even to signal relations between their own ideas and somebody else's. This is the case of the author of the thesis in Example 15 , who uses a relatively low number of both contrastive (78) and causal DMs (only 31 ) as compared to the other authors, even those within the same subcorpus. The example illustrates two of the ten different causal markers the author uses, although some of these occur only once in the whole work; this is the case with accordingly, as illustrated above.

(16) Though the performances were not filmed again, the final discussion was very interesting and lively, as the students fully identified with their new identities and situations. Although, the organization of the project in this mixed ability class was rather complicated and difficulties were also encountered with making the students start the activities, finally, they got fully involved in and enjoyed the project.

2.3 Spanish Armada Integra Grammar School in Brno 
Even though, the performances were not as lively as in the 'Exploration overseas' project, students used a considerable amount of the newly gained information. Discussions took place after each performance; however, it was sometimes difficult to make students transmit their attention from watching the performances to discussing them. A great advantage and help would be to film the performances and use the recordings in the final discussion.

The extra task was not done, as only two lessons block was allotted.

Even though it was difficult to make the students do any activity, finally they actively participated, acquired the basic facts and enjoyed the whole project, mainly the role plays.

(Methodology, Text 4)

This final example is taken from a methodology thesis. It shows three different tokens of contrastive DMs expressing hypotactic relations, namely although, even though, and though (listed by frequency of occurrence in the methodology subcorpus), and two tokens of the hypotactic causal marker as, the most common one not only in methodology theses but in the corpus as a whole. In addition, two markers in Example 16 illustrate a typical mistake made by novice writers, namely the use of a comma after a hypotactic marker, as evidenced by the commas after although and even though in bold (for a similar mistake, see Example 7 above); this type of mistake, caused in my opinion by a student's inability to distinguish between conjunctions and adverbs, occurs above all in the methodology theses.

Let me now summarise briefly some of the most typical mistakes the novice writers included in the investigation tend to make:

1. Some students are not able to use some of the selected DMs correctly.

2. Some students are not able to distinguish between hypotactic and paratactic markers (e.g. though as a conjunction and though as an adverb), especially in methodology theses and also in literature and culture theses.

3. Some students tend to overuse certain of the selected DMs, while introducing every other discourse segment with a marker, above all in linguistics theses.

4. Most students give preference to the use of only a limited repertoire of DMs, e.g. although, but, however, and on the other hand to express contrastive relations, and as, because, and therefore and/or thus to express causal relations, especially in methodology theses.

5. Some students sometimes use markers (e.g. anyway and though as a hypotactic marker) which are appropriate in informal spoken rather than formal written discourse.

\section{Conclusion}

The investigation has illustrated that expressing causal and contrastive relationships between adjacent or more distant segments of discourse is especially impor- 
tant in academic prose including novice academic writing, where authors/writers consider it of great importance to organize their discourses in harmony with their communicative intentions and expect their reader(s) to interpret the message accordingly. By signalling how the author intends the basic message that follows to relate to the prior segment(s) of discourse, the markers selected for the inquiry unambiguously contribute to both cohesion and coherence and are thus important for a student's adequate knowledge of a foreign language. Thus it is not surprising that an appropriate knowledge of DMs including those under investigation here is commonly listed among language phenomena that are practised in courses of academic writing at universities and often mentioned by authors of manuals of English academic style (Bennett 2009).

The analysis has proved that causal and contrastive relations tend frequently to be expressed overtly in novice academic writing, in particular by certain paratactic markers, such as therefore and thus when expressing causal relations, and but and however when expressing contrastive relations. These markers enable the natural ordering of discourse segments, i.e. the placement of segments with a 'grounding function' (Altenberg 1986) first and therefore before segments which provide new and/or unexpected information. Hypotactic DMs of both semantic classes under investigation are also common. With causal relations, they are slightly more frequent than paratactic markers, whereas with contrastive relations, they are much less frequent (about four times), although hypotactic relations are, as a rule, overtly signalled by a marker (Taboada 2006). Based on the results presented above it can now be concluded that there are differences between the individual markers, which are due in particular to differences in the knowledge of individual students and consequently preferences in writing habits; these can be influenced by overt instructions provided by teachers of academic writing and thesis supervisors.

The study has also proved that novice non-native speakers of English apply some of the selected markers incorrectly. In addition, some of them tend to use only a limited repertoire of the markers at their disposal, which might be caused by exposure to overt teaching of certain markers only. Although there are differences between the works of students writing their Master's theses in the different fields of study, my findings suggest that these mostly stem from the preferences of individual students. Last but not least, it must be emphasized that the study of DMs and their correct use in academic written discourse should be paid sufficient attention in a student's education, notably at advanced levels of languagelearning such as university level.

\section{Notes}

1 This article is part of the grant project 405/08/0866 Coherence and Cohesion in English Discourse, which is supported by the Czech Science Foundation.

2 In agreement with Fraser (1999: 938) the term 'discourse segment' ('segment of discourse') 
is used here "as a cover term to refer to 'proposition', 'sentence', 'utterance' and 'message' unless more specificity is required".

3 For a broad discussion of the terms commonly used to refer to DMs, see Povolná (2008) and (2010).

$4 \quad$ All DMs in bold letters indicate students' mistakes.

5 Although if is primarily considered to be conditional, in combination with even if it may be used "in a context when a complement of if is known to be true (Huddleston and Pullum 2002: 737), as in the example You don't have to defend everything Ed does, even if he is your brother, in which, as the authors hold the view that "the conditional is pragmatically equivalent to a concession". Since the same applies to the occurrences of even if found in the data analysed, this marker has been included in the analysis.

\section{References}

Altenberg, Bengt (1986) 'Contrastive Linking in Spoken and Written English'. In: Tottie, Gunnel and Ingegerd Bäcklund (eds.) English in Speech and Writing. A Symposium. Uppsala: Almqvist \& Wiksell, 13-40.

Bennett, Karen (2009) 'English Academic Style Manuals: A Survey'. Journal of English for Academic Purposes 8, 43-54.

Biber, Douglas, Stig Johansson, Geoffrey Leech, Susan Conrad, and Edward Finegan (1999) Longman Grammar of Spoken and Written English. London: Longman.

Bublitz, Wolfram (1999) 'Introduction: Views on Coherence'. In: Bublitz, Wolfram, Uta Lenk, and Eija Ventola (eds.) Coherence in Spoken and Written Discourse. Amsterdam: John Benjamins, 1-7.

Bublitz, Wolfram (1988) Supportive Fellow-Speakers and Cooperative Conversations. Discourse Topics and Topical Actions. Participant Roles and 'Recipient' Action on a Particular Type of Everyday Conversation. Amsterdam/Philadelphia: John Benjamins.

Chamonikolasová, Jana (2005) 'Comparing the structures of academic texts written in English and Czech'. In: Huttová, Maria et al (eds.) Slovak Studies in English 1. Bratislava: Comenius University, 77-84.

Dontcheva-Navratilova, Olga (2009) 'Evaluation in Non-Native Writer's Academic Discourse: Stance Devices'. In: Hanušová, Světlana a kol. Research in English Teacher Education. Brno: Masaryk University, 33-42.

Dontcheva-Navratilova, Olga (2012) 'Lexical Bundles in Non-Native Speakers' Academic Texts'. Brno Studies in English. The present issue.

Dontcheva-Navratilova, Olga (2007) 'On Coherence in Written Discourse'. In: Schmied, Josef, Christoph Haase, and Renata Povolná (eds.) Complexity and Coherence. Approaches to Linguistics Research and Language Teaching. REAL Studies 3. Göttingen: Cuvillier Verlag, 127-145.

Dušková, Libuše, Zdenka Strnadová, Dagmar Knittlová, Jaroslav Peprník, and Jarmila Tárnyiková (1988) Mluvnice současné angličtiny na pozadí češtiny. Praha: Academia.

Firbas, Jan (1992) Functional Sentence Perspective in Written and Spoken Communication. Cambridge: Cambridge University Press.

Flowerdew, Lynne (2004) 'The Argument for Using English Specialized Corpora to Understand Academic and Professional Language.' In: Connor, Ulla and Thomas Upton (eds.) Discourse in the Professions. Amsterdam/Philadelphia: John Benjamins, 11-33.

Fowler, Roger (1986) Linguistic Criticism. Oxford: Oxford University Press.

Fraser, Bruce (1990) 'An Approach to Discourse Markers'. Journal of Pragmatics 14, 383-395.

Fraser, Bruce (1999) 'What are Discourse Markers?' Journal of Pragmatics 31, 931-952.

Haberlandt, Karl (1982) 'Reader Expectations in Text Comprehension'. In: Le Ny, Jean-François and Walter Kintsch (eds.) Language and Comprehension. Amsterdam: North-Holland Publishing Company, 239-249. 
Halliday, Michael A. K. and Ruqaiya Hasan (1989) Language, Context, and Text: Aspects of Language in a Social-Semiotic Perspective. $2^{\text {nd }}$ ed. Oxford: Oxford University Press.

Hoey, Michael (2001) Textual Interaction. An Introduction to Written Discourse Analysis. London and New York: Routledge.

Huddleston, Rodney and Geoffrey K. Pullum (2002) The Cambridge Grammar of the English Language. Cambridge: Cambridge University Press.

Kortmann, Bernd (1991) Free Adjuncts and Absolutes in English. London: Routledge.

Miššíková, Gabriela (2005) 'Background Knowledge in Interpretation of Discourse.' In: Povolná, Renata and Olga Dontcheva-Navratilova (eds.) Discourse and Interaction 1. Brno Seminar on Linguistic Studies in English: Proceedings. Sbornik praci Pedagogické fakulty Masarykovy univerzity v Brně. Vol. 187. Brno: Masaryk University, 85-97.

Povolná, Renata (2007) 'Aspects of Coherence in Spoken Discourse'. In: Schmied, Josef, Christoph Haase, and Renata Povolná (eds.) Complexity and Coherence: Approaches to Linguistic Research and Language Teaching. REAL Studies 3. Göttingen: Cuvillier Verlag, 107-125.

Povolná, Renata (2009) 'Exploring Interactive Discourse Markers in Academic Spoken Discourse'. In: Dontcheva-Navratilova, Olga and Renata Povolná (eds.) Coherence and Cohesion in Spoken and Written Discourse. Newcastle: Cambridge Scholars Publishing, 60-80.

Povolná, Renata (2010) Interactive Discourse Markers in Spoken English. Brno: Masaryk University.

Povolná, Renata (2008) 'Why Are There So Many Labels for Discourse Markers?' Discourse and Interaction 1 (1), 115-124.

Seidlhofer, Barbara and Henry G. Widdowson (1999) 'Coherence in Summary: The Contexts of Appropriate Discourse'. In: Bublitz, Wolfram, Uta Lenk, and Eija Ventola (eds.) Coherence in Spoken and Written Discourse. How to Create it and How to Describe it. Amsterdam/Philadelphia: John Benjamins, 205-219.

Schiffrin, Deborah (1987) Discourse Markers. Cambridge: Cambridge University Press.

Taboada, Maite (2006) 'Discourse Markers as Signals (or Not) of Rhetorical Relations'. Journal of Pragmatics 38 (4), 567-592.

Tárnyiková, Jarmila (2007) Sentence Complexes in Text. Processing Strategies in English and in Czech. Olomouc: Palacký University.

Vogel, Radek (2008) 'Sentence Linkers in Essays and Papers by Native vs. Non-Native Writers'. Discourse and Interaction 1 (2), 119-126.

Wagner, Susanne (2011) 'Concessives and Contrastives in Student Writing: L1, L2 and Genre Differences'. In: Schmied, Josef (ed.) Academic Writing in Europe: Empirical Perspectives. REAL Studies 5. Göttingen: Cuvillier Verlag, 23-48.

Renata Povolná is Associate Professor of English Linguistics at Masaryk University, Brno, Czech Republic. She specializes in discourse analysis, pragmatics, and conversation analysis, concentrating mainly on academic discourse, both spoken and written. She is currently involved in the research project Coherence and Cohesion in English Discourse, the aim of which is to conceptualize coherence and cohesion as constitutive components of human communication and to apply theoretical insights to the analysis of spoken and written discourse. She co-edits the linguistic journal Discourse and Interaction.

Address: Doc. PhDr. Renata Povolná, Ph.D., Department of English Language and Literature, Faculty of Education, Masaryk University, Poříči 9, 60300 Brno, Czech Republic. [e-mail: povolna@, ped.muni.cz] 